\title{
Is the future of meat palatable? Perceptions of in vitro meat as evidenced by online news comments
}

\author{
Linnea I Laestadius ${ }^{1, *}$ and Mark A Caldwell ${ }^{2}$ \\ 'Joseph J. Zilber School of Public Health, University of Wisconsin-Milwaukee, 1240 N. 10th Street, Milwaukee, \\ WI 53205, USA: ${ }^{2}$ Department of Sociology, University of Wisconsin-Milwaukee, Milwaukee, WI, USA
}

Submitted 15 March 2014: Final revision received 11 November 2014: Accepted 23 January 2015: First published online 30 March 2015

\begin{abstract}
Objective: To understand current public perceptions of in vitro meat (IVM) in light of its potential to be a more environmentally sustainable alternative to conventional meat. Design: A qualitative content analysis of the comments made on online news articles highlighting the development of IVM and the world's first IVM hamburger in August 2013.

Setting: News article comment sections across seven US-based online news sources (The New York Times, The Los Angeles Times, The Washington Post, The Wall Street Journal, USA Today, Cable News Network and National Public Radio). Subjects: Four hundred and sixty-two commenters who made eight hundred and fourteen publicly available online comments addressing IVM.

Results: Key themes in commenter perceptions of IVM included environmental and public health benefits, but also negative themes such as IVM's status as an unnatural and unappealing food. Overall, the tone of comments was more negative than positive.

Conclusions: Findings suggest that while the environmental and public health motivations for developing and in turn consuming IVM resonate with some segments of the population, others find that reasoning both uncompelling and problematic. Concerns about IVM as an unnatural and risky product also appear to be a significant barrier to public acceptance of IVM. Supporters of IVM may wish to begin to develop a regulatory strategy for IVM to build public trust and explore messaging strategies that cast IVM as a new technology with benefits to individuals rather than primarily a solution to global challenges. Those in the public health nutrition field can make an important contribution to the emerging public discussion about IVM.
\end{abstract}

Keywords

Meat consumption

In vitro meat

Public opinion
At a London-based media event in August 2013, a chef prepared the world's first hamburger made from in vitro or 'lab grown' meat. While in vitro meat (IVM) has been in development for a number of years and is not yet available to consumers, this represented the most public unveiling of this new form of meat to date. IVM is produced from the culturing of animal muscle cells in a controlled environment ${ }^{(1)}$. Accordingly, it is projected that the majority of the environmental concerns associated with livestock would be avoided with $\operatorname{IVM}^{(2)}$. IVM has been hailed by some as the future of meat, primarily as researchers anticipate that it would use fewer resources and would be substantially less emission-intensive than meat derived from conventionally raised farm animals ${ }^{(2)}$. This expected benefit is of particular importance as livestock production already accounts for $14.5 \%$ of human-created global greenhouse gas emissions $^{(3)}$. Given the significance of climate change to the food system and public health more generally, the field of public health nutrition has begun to move to make 'environmental impact, including climate change and its implications... the centre of [its] learning, teaching, practice and advocacy ${ }^{(4)}$ (p. 302). As such, the public health nutrition community should be aware of developments with IVM and may play an important role in shaping public perceptions of IVM.

It should of course be noted that a switch from conventional meat to IVM is also anticipated to have more direct public health nutrition effects. IVM could be engineered to be higher in polyunsaturated fats and lower in saturated fats ${ }^{(1,5)}$. The ability to engineer the biochemical composition of meat is of clear relevance to public health nutrition given the link between red and processed meats and conditions such as heart failure and cancer ${ }^{(6-8)}$. Further, it is reported that IVM holds the potential to 
reduce the spread of food-borne illnesses ${ }^{(1,5)}$. The importance of all of these predicted benefits is compounded by the fact that the FAO estimates that global demand for meat will increase $73 \%$ from 2010 levels by $2050^{(3)}$. Thus, it appears that bringing IVM to market may facilitate notable benefits for both environmental sustainability and public health nutrition.

Yet for all of its potential environmental and public health promise, public acceptance of IVM remains unclear. Straddling the line between an emerging technology and a common foodstuff, IVM represents something novel both for consumers and public health researchers. While there is a growing body of literature considering the possible social and environmental implications of IVM, there has been little in the way of analysis of public acceptance of $\operatorname{IVM}^{(9,10)}$. There is a need to understand current public perceptions of IVM in order to inform long-term strategic planning for more sustainable and healthy diets. This is to say that, in addition to the need for further research on IVM's technical feasibility and final environmental and nutritional profile, there is also a clear need for research on the feasibility of consumer acceptance of IVM. As noted by Haagsman et al. ${ }^{(9)}$, 'consumer acceptance is of utmost importance [to IVM]; without it there may be a product but no market' (p. 38). Further, identifying opportunities and challenges arising from perceptions of IVM may also help inform the development, marketing and regulation of IVM.

The present study seeks to begin to understand public perceptions of this novel foodstuff in light of its potential benefits for environmental sustainability and public health nutrition through a qualitative content analysis of online comments posted in response to news stories about the aforementioned 2013 IVM hamburger event. Online comments on news articles have been recognized as a particularly valuable means of documenting true public opinion without researcher intervention ${ }^{(11)}$. In addition to capturing social norms and perceptions around IVM, we sought to assess incivility in the discourse surrounding IVM in light of recent research highlighting incivility's polarizing effects on risk perceptions of emerging technologies $^{(12)}$. To conclude, we examine the practical implications of current public perceptions of IVM.

\section{Public exposure to in vitro meat}

Prior to the IVM hamburger event in 2013, the preparation of IVM for consumption had been publicized only a small number of times and with relatively minimal media attention $^{(13-15)}$. Unlike these prior instances, the 2013 event was explicitly designed to draw mainstream media attention and illustrate IVM as a consumer-targeted product rather than a research novelty. The level of media coverage of this event makes it particularly well suited as a case study for examining public perceptions of IVM.

Some background on the event is provided in order better understand the context within which the public formed opinions on IVM. The cultured beef for the in vitro hamburger was grown by Professor Mark Post in his lab at Maastricht University. Fetal bovine serum was used in the medium to grow the IVM, indicating a continued reliance on animals at this stage in IVM's development. Consisting of approximately 20000 muscle strands mixed with 'a little egg powder and breadcrumbs and a few other common burger ingredients', the hamburger was prepared by a prominent British chef and eaten in front of an audience of 200 journalists and academics on 5 August $2013^{(16)}$. The hamburger cost approximately €250 000 (\$US 345250 ) to produce and Post estimated that additional production could occur at a cost of about $\$ \mathrm{US} 70 / \mathrm{kg}$ with current technology; however, it was stressed that in the long term IVM 'could be cheaper than conventionally farmed beef, and certainly better for the environment' ${ }^{(16)}$. Tasters of the hamburger noted in particular that the hamburger's current lack of fat was an area for future work due to the importance of fat in the flavour of meat ${ }^{(17)}$. During the event it was suggested that IVM might be commercially available in as little as a decade.

\section{Researcher and public perspectives on in vitro meat}

Below we briefly examine the positive and negative perceptions of IVM found in the growing body of literature examining the environmental, ethical and social implications of this emerging technology. It should be stressed most of the prior non-lab work focused on IVM is primarily speculative and theoretical in nature. The few exceptions that have examined public and media perceptions are: (i) Marcu et al. ${ }^{(10)}$, who examined participant responses to a video titled 'Would You Eat Synthetic Meat?'; (ii) van der Weele and Driessen ${ }^{(18)}$, in which conference workshop participants envisioned 'moral profiles' for IVM; (iii) Chiles ${ }^{(19)}$, which considered stakeholder and media representations of IVM; and (iv) Goodwin and Shoulders ${ }^{(20)}$, who examined news media coverage of IVM. As such, much of the current understanding of responses to IVM comes from the perspectives of researchers rather than empirical data from members of the public.

Most commonly, researchers have raised questions about the degree of 'unnaturalness' of IVM and how receptive the public might be to a lab-grown foodstuff. Researchers have referenced IVM within the context of figures such as Frankenstein's monster and zombies $^{(9,13,21)}$, suggesting concern with science run amok or unknown negative risks. Marcu et al. ${ }^{(10)}$ (p. 8) found evidence of these sentiments in response to a descriptive video about IVM and suggest that these science-fiction metaphors are drawn from 'futuristic dystopian human societies as depicted in science-fiction films' and help individuals make sense of novel technologies such as IVM. Some researchers also noted there is a 'yuck factor' related to the perceived unnaturalness and technological nature of $\operatorname{IVM}^{(20,22)}$. The suggestion of perceived unnaturalness is very much in line with empirical data on public 
perceptions of other emerging technologies, such as geoengineering and GM organisms ${ }^{(23-25)}$. Possible perceptions of unnaturalness are of particular interest given the success that food activists had with labelling GM organisms as 'Frankenfoods' in their efforts to prevent adoption of GM organisms in Europe ${ }^{(26)}$.

Researchers and members of the public have also expressed concern with the fact that IVM currently tastes different from and lacks the correct texture of a conventional piece of meat ${ }^{(1,9,10)}$. While these taste concerns were expressed prior to the IVM hamburger event, the responses of the hamburger taste testers indicate that this remains an area where further work is needed. Other potential concerns articulated by researchers include IVM costing more to produce than conventional meat ${ }^{(1,27)}$, causing significant changes to agricultural economies if it becomes commercially viable ${ }^{(28,29)}$ and leading to increased industry consolidation and corporate power in the food system ${ }^{(18,21)}$. Marcu et al. ${ }^{(10)}$ also found that some individuals rejected IVM entirely as they felt that it was an unnecessary development.

With regard to positive outcomes, researchers highlight IVM's potential to reduce environmental damage relative to conventional meat production, reduce animal suffering and the spread of zoonotic disease, improve food security and provide a form of meat with fewer health risks related to food-borne illnesses and saturated fats ${ }^{(1,9,22,28,29)}$. Of these, benefits to the environment are most prominent in the literature, with a life-cycle assessment indicating that IVM could reduce usage of fossil fuels, staple crops and arable land, while simultaneously reducing greenhouse gas emissions ${ }^{(2)}$. Interestingly, the participants examined by Marcu et al. ${ }^{(10)}$ make few mentions of the potential benefits of IVM, although this may be a function of these authors' focus on 'sense-making processes' rather than IVM specifically. Finally, and perhaps most importantly with regard to public acceptance of IVM, is the suggestion that IVM will appeal to meat eaters in a way that plantbased mock meats cannot. IVM would allow people to continue to eat 'real, genuine meat' with few of the negatives traditionally associated with meat ${ }^{(22)}$ (p. 582).

\section{Online comment analysis}

Given the relatively recent nature of this methodological approach, a brief examination of online news comment analysis as a means of understanding public perceptions and social norms is warranted. Comments on news articles have been recognized as a valuable source of public opinion data since at least 2003 and several studies have now been informed by the analysis of comments on online news sources ${ }^{(30-34)}$. Regan et al. ${ }^{(35)}$, for example, examined risk perceptions of meat in online comments. News comments are particularly valuable to this type of research because they so frequently include the views of the commenters. Indeed, in a broad analysis of online comments across multiple topics and publications, Paskin ${ }^{(36)}$ found that the vast majority of comments were comprised solely of commenter opinions rather than the provision of any new information relevant to the coverage of a news story.

It should of course be noted that commenters are a selfselected group and not necessarily representative of the general public or online readers in either demographics or opinions. However, as a means of identifying and exploring themes within public perceptions of IVM, online comment analysis holds several unique benefits. Among others, comment analysis eliminates several potential sources of bias stemming from researcher engagement in the data collection process ${ }^{(11,32)}$. Commenters may also be more likely to offer their true opinions on an issue since the fear of repercussions is limited by anonymity, allowing comments to serve as 'reflections of society's pulse (37) (p. 194). Thus, while they may not be generalizable to a clear population, they are valuable because they represent the way in which 'some people' react to a topic ${ }^{(34,35)}$ (p. 311). Online comments are also important for study as they may influence public perceptions in their own right $^{(32,38)}$. For example, research indicates that incivility in news comments leads to polarization in risk perception of a technology, which is particularly concerning for emerging technologies such as $\mathrm{IVM}^{(12)}$. Overall, comment analysis has been identified as a valuable but to date underutilized approach to exploring public perceptions of public health questions ${ }^{(32)}$.

\section{Methods}

\section{Data collection}

The top five online daily newspapers by average combined digital and print circulation ${ }^{(39)}$, adjusted to avoid geographical over-representation," were selected for analysis: The Wall Street Journal, The New York Times, USA Today, The Los Angeles Times and The Washington Post. To supplement this and offer greater diversity in readership, we selected two additional online news sources: the websites for Cable New Network (CNN) and National Public Radio (NPR). We searched each site using the terms 'in-vitro meat', 'lab AND meat', 'cultured AND meat', 'synthetic AND meat', 'cultured AND hamburger' and 'synthetic AND hamburger' to gather relevant articles and editorials (collectively 'articles') addressing the IVM hamburger event published between 1 August and 31 August 2013. The number of public comments on each IVMfocused article was noted. The article with the highest number of comments from each news source was chosen for analysis. From each chosen article, we collected comments and comment replies (collectively 'comments'), beginning with the earliest comment chronologically

* The New York Daily News and New York Post, which have higher average
circulation numbers than The Washington Post, were excluded from circulation
analysis. 
(e.g. posted soonest after article publication), until either: (i) the discourse included comments from 100 unique commenters; or (ii) we ran out of comments to gather. This approach was chosen over a fixed comment count in order to account for the fact that many individuals commented on an article multiple times, as determined by the presence of multiple comments from the same screen name.

All comments were entered into a Microsoft ${ }^{\circledR}$ Excel database consisting of screen names, times and dates of posting, comments, and if the comment was made in reply to a previous comment. Comments determined to be clearly irrelevant to any aspect of IVM were discarded after joint discussion between L.I.L. and M.A.C. and not included for analysis. When the exclusion of comments reduced the number of individual commenters in the sample to below 100, additional comments were coded as necessary. We numbered included comments to maintain contextual information on the order of comments in a thread, sorted by author screen name, and imported comments into HyperRESEARCH 3.5.2 (ResearchWare, Randolph, MA, USA) for analysis.

\section{Analysis}

Each included comment was coded for analysis as per content analysis procedures. Content analysis is a systematic means of developing 'concepts or categories describing [a] phenomenon' through the classification of text into 'much smaller content categories, ${ }^{(40)}$ (pp. 108-109). The codes for the analysis were generated through both deductive and inductive approaches. Deductive codes were developed from an examination of common themes raised in the prior IVM literature. In order to enable the capture of additional themes not represented in prior literature, an inductive approach informed by grounded theory principles was also used to develop additional codes ${ }^{(41)}$. This approach relies upon constant comparison of data and codes to move from codes that closely reflect specific instances in the data to more inclusive codes and themes ${ }^{(41)}$. In addition to the thematic codes, we coded comments for tone towards IVM and civility of discourse. In order to avoid over-representing the views of individuals who commented multiple times, commenters (rather than individual comments) served as the unit of analysis for the examination of perceptions of IVM.* However, as civility and tone were found to vary by comment rather than commenter, these were examined on a commentby-comment basis. Additionally, considering these at

* Prior literature has suggested coding only the first comment from each commenter. However, frequently the first comment made was not richest with regard to content. Additionally, commenters at times made multiple comments right below each other rather than including all of their opinions in one larger comment. Thus the selection of only the first comment results in a somewhat arbitrary cut-off point and also would have prevented a full analysis of civility in interactions between commenters. As an alternative approach, we have utilized commenters, operationalized as all of the comments made by the same screen name, as the primary unit of analysis. the comment level gives a better understanding of the overall comment environment that readers are exposed to. While civility is somewhat subjective, cues for assigning an uncivil code were drawn from Papacharissi ${ }^{(42)}$ and Anderson et $a l^{(12)}$ and included, among others, ad hominem attacks on other commenters, sarcasm, cursing, using all-capital letters, political stereotyping and inflammatory language.

Initially, we coded 100 comments from one article with: (i) the pre-established literature codes; (ii) inductive theme codes emerging from the comments and not reflected in the literature codes; and (iii) tone and civility codes. Comments could also be coded as irrelevant to the study if they were part of a comment thread that evolved in a manner that made reply comments no longer relate to any aspect of IVM. These comments were still coded for civility, however. Initial comments were double-coded independently by L.I.L. and M.A.C. We discussed coded comments to ensure consistent application of the preestablished codes and to jointly agree on additions or changes to the codebook. Coding reflected an iterative process of constant comparison and, as such, the literature-based codes were not privileged in any way and also evolved together with inductive codes through this process. Thus, the final coding scheme reflected only the pre-established literature codes to the extent that they were actually relevant to the data. This codebook was then applied to the remaining articles, with new codes allowed to develop through joint discussion as needed. We double-coded $10 \%$ of the comments on each article to ensure codes were applied consistently, with discrepancies resolved through discussion and amendments to the codebook as needed. Coding was an iterative process and thus data were recoded based upon changes to the codebook. A final quality control check of all theme codes was completed by L.I.L. Suggested changes were reviewed and approved by M.A.C. before finalization. Upon completion of coding, common response themes and sub-themes were identified.

\section{Findings}

Seven articles, one from each news source, were selected for analysis. A total of 814 comments from 462 commenters were included for analysis. See Table 1 for the chosen articles, article themes and the number of comments originating from each article. The CNN article was the only article explicitly arguing in favour of IVM. Through coding and analysis, we identified eight primary IVM themes, comprised of multiple sub-themes. Table 2 provides an overview of the primary themes, as well as sub-themes key to understanding the primary themes. Sub-themes with an asterisk are also clearly identified or discussed in prior IVM literature. Eleven per cent ( $n$ 93) of the coded comments were found to be irrelevant. 
Table 1 In vitro meat (IVM) news articles and number of comments; qualitative content analysis of comments in news article comment sections across seven US-based online news sources, 1 August to 31 August 2013

\begin{tabular}{|c|c|c|c|c|c|c|c|c|c|c|c|c|}
\hline \multirow[b]{2}{*}{$\begin{array}{l}\text { News } \\
\text { platform* }\end{array}$} & \multirow[b]{2}{*}{ Article title } & \multirow[b]{2}{*}{ Date } & \multirow[b]{2}{*}{$\begin{array}{l}\text { Total article } \\
\text { comments }\end{array}$} & \multirow[b]{2}{*}{$\begin{array}{l}\text { Comments } \\
\text { included for } \\
\text { analysis }\end{array}$} & \multirow[b]{2}{*}{$\begin{array}{c}\text { Unique } \\
\text { commenters among } \\
\text { included comments }\end{array}$} & \multicolumn{7}{|c|}{ Article describes: } \\
\hline & & & & & & $\begin{array}{c}\text { IVM } \\
\text { development }\end{array}$ & $\begin{array}{l}\text { Taste- } \\
\text { tester } \\
\text { response }\end{array}$ & $\begin{array}{l}\text { 'Yuck' } \\
\text { factor }\end{array}$ & $\begin{array}{l}\text { Environmental } \\
\text { benefits }\end{array}$ & $\begin{array}{l}\text { Animal } \\
\text { welfare } \\
\text { benefits }\end{array}$ & $\begin{array}{l}\text { Food } \\
\text { safety } \\
\text { benefits }\end{array}$ & $\begin{array}{l}\text { Food } \\
\text { security } \\
\text { benefits }\end{array}$ \\
\hline CNN & $\begin{array}{l}\text { Why your burger should } \\
\text { be grown in a lab }\end{array}$ & 9 August & 1124 & 209 & 100 & $x$ & $x$ & $x$ & $x$ & $x$ & $x$ & \\
\hline NPR & $\begin{array}{l}\text { Long awaited lab-grown } \\
\text { burger is unveiled in } \\
\text { London }\end{array}$ & 5 August & 295 & 254 & 100 & $x$ & $x$ & $x$ & $x$ & $x$ & & \\
\hline LAT & $\begin{array}{l}\text { Lab-grown burger from } \\
\text { stem cells introduced: } \\
\text { Looks good, tastes } \\
\text { blah }\end{array}$ & 5 August & 12 & 11 & 7 & $x$ & $x$ & & $x$ & $x$ & & $x$ \\
\hline NYT & $\begin{array}{l}\text { A lab-grown burger gets } \\
\text { a taste test }\end{array}$ & 5 August & 313 & 127 & 100 & $x$ & $x$ & & $x$ & $x$ & & $x$ \\
\hline WSJ & $\begin{array}{l}\text { Scientists cook up lab- } \\
\text { grown beef burger: } \\
\text { project was funded by } \\
\text { Google co-founder }\end{array}$ & 5 August & 55 & 51 & 36 & $x$ & $x$ & & $x$ & & & \\
\hline WAPO & $\begin{array}{l}\text { Lab-grown beef taste } \\
\text { test: 'Almost' like a } \\
\text { burger }\end{array}$ & 5 August & 99 & 93 & 62 & $x$ & $x$ & $\mathrm{x}$ & $x$ & $x$ & $x$ & $x$ \\
\hline \multirow[t]{2}{*}{ USA } & $\begin{array}{l}\text { Lab-made beef gets } \\
\text { taste test }\end{array}$ & 5 August & 72 & 69 & 57 & $x$ & $x$ & & $x$ & $x$ & & $x$ \\
\hline & & Total comments & 1970 & 814 & 462 & 7 & 7 & 3 & 7 & 6 & 2 & 4 \\
\hline
\end{tabular}

*CNN, Cable Network News; NPR, National Public Radio; LAT, The Los Angeles Times; NYT, The New York Times; WSJ, The Wall Street Journal; WAPO, The Washington Post, USA, USA Today. 
Table 2 Primary themes and key sub-themes identified, with number and percentage of commenters; qualitative content analysis of comments about in vitro meat (IVM) in news article comment sections across seven US-based online news sources, 1 August to 31 August 2013

\begin{tabular}{|c|c|c|}
\hline Primary themes and key sub-themes & $\begin{array}{l}\text { Number of } \\
\text { commenters }\end{array}$ & $\%$ of all commenters \\
\hline Impact on animals & 61 & 13 \\
\hline IVM will be better for animals* & 30 & 6 \\
\hline Defence of killing animals for food & 23 & 5 \\
\hline Concern for fate of animals if no longer needed for food* & 10 & 2 \\
\hline Dystopian vision & 72 & 16 \\
\hline IVM tied to cannibalism* & 45 & 10 \\
\hline IVM is being developed for suspicious or greedy reasons & 17 & 4 \\
\hline Fear of forced IVM consumption & 15 & 3 \\
\hline Impact on environment & 76 & 16 \\
\hline IVM will be more sustainable than conventional meat production* & 37 & 8 \\
\hline Conventional meat production bad for environment (without reference to IVM) & 22 & 5 \\
\hline IVM will be less sustainable than conventional meat production & 12 & 3 \\
\hline IVM not needed & 53 & 11 \\
\hline Consumers should adopt vegetarian or vegan diets instead of $\mathrm{IVM}^{*}$ & 17 & 4 \\
\hline Consumers should eat less meat instead of IVM* ${ }^{*}$ & 12 & 3 \\
\hline Consumers should eat 'better' (e.g. organic, grass-fed or free-range) meats instead of IVM & 14 & 3 \\
\hline Impact on public health & 85 & 18 \\
\hline IVM will help reduce food insecurity* & 14 & 3 \\
\hline IVM will be less nutritious than conventional meat ${ }^{*}$ & 12 & 3 \\
\hline IVM will have less fat than conventional meat* & 11 & 2 \\
\hline IVM will be healthier/more nutritious than conventional meat* & 9 & 2 \\
\hline IVM will pose food safety risk & 7 & 2 \\
\hline IVM will improve food safety ${ }^{*}$ & 6 & 1 \\
\hline New scientific development & 205 & 44 \\
\hline IVM is an unnatural scientific development* & 55 & 12 \\
\hline Expressing excitement, joy or pride in the scientific process in light of IVM development & 45 & 10 \\
\hline Faith in scientific process leading to IVM being more affordable and better tasting the future & 42 & 9 \\
\hline Conventional meat production is already unnatural ${ }^{\star}$ & 34 & 7 \\
\hline $\begin{array}{l}\text { IVM will result in unknown or unanticipated negative risks to humans and/or the } \\
\text { environment }^{*}\end{array}$ & 21 & 5 \\
\hline Science has replicated real meat & 20 & 4 \\
\hline IVM as a culinary development & 97 & 21 \\
\hline Disgust at the idea of IVM for human consumption* & 44 & 10 \\
\hline IVM will appeal to current meat eaters* ${ }^{*}$ & 15 & 3 \\
\hline IVM will have an inferior taste and/or texture relative to conventional meat ${ }^{*}$ & 10 & 2 \\
\hline IVM will taste as good as, if not better than, conventional meat & 10 & 2 \\
\hline Structural-economic considerations & 49 & 11 \\
\hline Non-rhetorical questions about IVM & 23 & 5 \\
\hline Discussions of use and implications of fetal calf serum* & 22 & 5 \\
\hline IVM will cost too much to be commercially viable* & 13 & 3 \\
\hline IVM will harm traditional agriculture* & 5 & 1 \\
\hline
\end{tabular}

${ }^{*}$ Sub-themes that are also clearly identified or discussed in prior IVM literature.

\section{Tone and civility}

Across all seven articles, $18 \%$ ( $n$ 146) of comments were positive towards the idea of IVM, 30\% ( $n$ 241) were negative, $5 \%$ ( $n$ 39) were sceptical but not opposed to IVM and 36\% ( $n$ 289) were neutral. The large number of neutral comments stems from the fact that many comment threads evolved into topics that were only tangentially related to IVM. Additionally, a number of commenters left comments with the intent of making a joke about IVM, resulting in multiple comments that lacked a clear opinion on IVM. Additionally, six comments were unable to be classified for tone, as the intent of the comment could not be fully discerned. Negative comments were more common than positive ones across all news sources except NPR and The Los Angeles Times.

The majority of comments were civil in nature. This was also consistent across all news sources. Seventy-five per cent of all comments ( $n$ 612) were civil, as compared with $25 \%$ that were interpreted as uncivil ( $n$ 202). Additionally, $10 \%$ ( $n$ 84) of all comments were classified as having a humorous intent. Comments that were positive in tone were more frequently civil than those that were negative in tone $(86 \% v .71 \%)$. Uncivil comments frequently included name calling, political stereotyping, inflammatory language and typing in all-caps (see for example Table 3, quotes 5 and 21).

\section{Primary themes and key sub-themes}

Each primary theme, as well as the sub-themes that were found to be most common among commenters, is highlighted below. Illustrative quotes are provided for each theme in Table 3. While themes largely echoed those predicted in the prior IVM literature, there were several 
Table 3 Illustrative quotes by theme; qualitative content analysis of comments about in vitro meat (IVM) in news article comment sections across seven US-based online news sources, 1 August to 31 August 2013

\begin{tabular}{|c|c|c|}
\hline $\begin{array}{l}\text { Quote } \\
\text { number }\end{array}$ & $\begin{array}{l}\text { News } \\
\text { source* }\end{array}$ & Quote† \\
\hline \multicolumn{3}{|c|}{ IVM's impact on animals } \\
\hline 1 & NPR & $\begin{array}{l}\text { 'This is brilliant technology in its infancy. Many comments here are akin to criticizing the Wright brothers' first } \\
\text { airplane for not featuring in-flight movies and overhead bins for carryon luggage. The potential is that in a } \\
\text { hundred years people may laugh at the old barbaric days when humans used to actually kill and eat mammals } \\
\text { and fish.' }\end{array}$ \\
\hline 2 & WAPO & $\begin{array}{l}\text { 'The fast track to extinction in the modern era is no longer being of use to man, meaning that the ultimate } \\
\text { "success" of this product would be the mass abandonment and extermination of the very species it is ostensibly } \\
\text { created to help. But, you know, science.' }\end{array}$ \\
\hline \multicolumn{3}{|c|}{ IVM as a dystopian vision } \\
\hline 3 & CNN & $\begin{array}{l}\text { 'We could also make use of corpse reclamation. Have some soylent green... It will become so popular that } \\
\text { demand will out pace supply, which will then solve prison overcrowding problems. Oh, I think I've seen this } \\
\text { movie/read this book before' }\end{array}$ \\
\hline 4 & USA & $\begin{array}{l}\text { 'What happens when (either inadvertently or deliberately) the sample tissue is substituted with human cells? Will } \\
\text { that mean partakers are cannibals? That could make the "finger in the chilli" story seem quite tame' }\end{array}$ \\
\hline 5 & NYT & $\begin{array}{l}\text { 'I wish the people pushing this garbage had to eat it at every meal for the rest of their lives. Air heads who think } \\
\text { vast profits, or fame, are far more important than delicious and healthy food have already ruined a huge } \\
\text { percentage of our food supplies. If this trend continues much longer, there won't be anything left that's fit to eat' }\end{array}$ \\
\hline \multicolumn{3}{|c|}{ IVM's impact on the environment } \\
\hline 6 & NYT & $\begin{array}{l}\text { 'I have been waiting for this for a long time as this will be a great environmental benefit if this were taken } \\
\text { commercial. The biggest issue will be educating the public that this is a better way to go. I am all for it' }\end{array}$ \\
\hline 7 & WSJ & $\begin{array}{l}\text { 'This experiment is not a zero-sum activity. The necessary nutrients, the workers, the laboratory etc. all require } \\
\text { much more energy than the product. There will be no benefit to the earth when the method is commercialized. A } \\
\text { cow is a very efficient machine. A group of humans have historically been shown to be inefficient and enormous } \\
\text { polluters' }\end{array}$ \\
\hline \multicolumn{3}{|r|}{ P } \\
\hline 8 & NYT & $\begin{array}{l}\text { 'Too much animal protein is a major cause of heart disease, cancer, diabetes, arthritis and other diseases that } \\
\text { plague us. Better to educate about healthful benefits of a plant- based diet. Vegetables, fruits, nuts and grains } \\
\text { provide all the protein we need. If we ate animal protein only once or twice per week, which is still more than our } \\
\text { bodies require, sustainability would not be an issue' }\end{array}$ \\
\hline 9 & LAT & 'This is no more disgusting than old-fashioned hamburger. Wise up and go vegan people!' \\
\hline 10 & NPR & $\begin{array}{l}\text { 'I agree it's not normal to raise animals for meat the way the industry does now, but this isn't normal either. For } \\
\text { those who must eat meat, there are other options beyond this false dichotomy: there's hunting, and there's } \\
\text { small-scale, humanely-raised meat.' }\end{array}$ \\
\hline \multicolumn{3}{|c|}{ IVM's impact on public health } \\
\hline 11 & NPR & $\begin{array}{l}\text { 'I would like to know the exact nutritional components of lab created food. I'll bet there aren't many. You cannot fool } \\
\text { Mother Nature-only stupid humans' }\end{array}$ \\
\hline 12 & NYT & $\begin{array}{l}\text { 'I'm also a cell biologist. The thought of consuming this "product" bathed in growth factors, steroids, fetal bovine } \\
\text { serum, and who knows what else makes me ill. But the point about viruses and other contaminants is one I had } \\
\text { had not considered-cells grown in the lab, removed from the cow or whatever host animal, will not have the } \\
\text { benefit of an immune system to prevent the proliferation of all sorts of human pathogens. This stuff will make } \\
\text { factory farm cattle, raised in the worst possible manner, seem like free range beef by comparison' }\end{array}$ \\
\hline 13 & CNN & $\begin{array}{l}\text { 'Personally, I don't think I would go for this; however, if costs can be vastly brought down, if this type of } \\
\text { technological innovation could really help stave off famine across the globe I'm all for it!' }\end{array}$ \\
\hline \multicolumn{3}{|c|}{ IVM as a new scientific development } \\
\hline 14 & USA & $\begin{array}{l}\text { 'I think this idea is interesting but rediculous. We were born to be meat eaters, and livestock was put on this earth } \\
\text { for us to eat. I'm the biggest animal lover there is but that fact doesn't change. III take a fresh steak over some } \\
\text { hocus pocus test tube burger every time!' }\end{array}$ \\
\hline 15 & WAPO & 'If saving a cow is more important to you than being a lab rat, go right ahead-LoL.' \\
\hline 16 & NYT & $\begin{array}{l}\text { '...so good for these scientists trying to do ground breaking work. I look forward to eating it someday. And for those } \\
\text { saying it's unnatural, well, most technology is unnatural. Nature didn't create cars, airplanes, or medicines. Yet } \\
\text { you wouldn't hestitate to use a plethora of technology.' }\end{array}$ \\
\hline \multicolumn{3}{|c|}{ IVM as a culinary development } \\
\hline 17 & USA & 'What a waste of money. Test tube beef sounds disgusting and I would never eat it much less feed it to my family' \\
\hline 18 & NPR & $\begin{array}{l}\text { 'gross. we can't trust where our food comes from anymore. i'd become a vegetarian before taking a bite out of this } \\
\text { lab-meat.' }\end{array}$ \\
\hline 19 & WAPO & $\begin{array}{l}\text { 'I'm actually psyched about this development. I have not eaten red meat for some years now, but it would be } \\
\text { delightful to be able to enjoy an ethical hamburger again some day. Even if it cost me } \$ 50 \text {, it would be worth it as } \\
\text { a once-a-year splurge' }\end{array}$ \\
\hline \multicolumn{3}{|c|}{ Structural-economic considerations and IVM } \\
\hline 20 & NYT & $\begin{array}{l}\text { 'One point here is unclear to me: what kind of "nutrient solution" was used. Typical cell cultures use sera from } \\
\text { animals (bovine or horse typically) to provide growth factors necessary to make the cells proliferate. If these } \\
\text { cells require serum, the whole point of being lab grown, animal-free, sustainable, etc is gone' }\end{array}$ \\
\hline 21 & USA & $\begin{array}{l}\text { 'And the price!? You guys are insane. This was a pointless experiment I doubt even superstars are going to spend } \\
\text { that money on a healthier burger when they can eat what they please and get lypo cheaper anyways' }\end{array}$ \\
\hline
\end{tabular}

*NPR, National Public Radio; WAPO, The Washington Post, CNN, Cable News Network; USA, USA Today, NYT, The New York Times; WSJ, The Wall Street Journal; LAT, The Los Angeles Times.

†All comments are directly transcribed, including any typographical errors. 
important distinctions. The themes of 'dystopian visions' and 'IVM not needed' were not commonly identified in prior IVM literature with the exception of Marcu et al. ${ }^{(10)}$, while the commenters' focus on environment and animals was smaller than would have been anticipated based on prior literature. It should be noted that themes and subthemes were not mutually exclusive, as several commenters touched on several themes. The theme of IVM as a new scientific development was consistently the most popular across news sources.

In vitro meat's impact on animals

Several commenters discussed issues related to the impact of IVM on animals. While most of these commenters addressed IVM's anticipated benefits to animal welfare and reductions in the number of animals slaughtered for food (Table 3, quote 1), others were more critical of the impacts of IVM on animals. Some raised questions about what would happen to farm animals if they were no longer needed for food production, while others defended the act of killing animals for food as a part of the natural order (quote 2). Additionally, a small number of commenters expressed concern that IVM would simply reinforce demand for meat.

\section{In vitro meat as a dystopian vision}

The dystopian vision theme was comprised of commenters who discussed IVM bringing about a new and problematic vision of the future or who distrusted the intentions of those supporting the development of IVM. We note that this theme goes beyond the discussions of dystopian science fiction found in Marcu et al. ${ }^{(10)}$. The theme as it is expressed here is not purely related to technological innovation but rather is heavily characterized by pessimism about human nature, political-economic systems and global environmental change. A large majority of these comments addressed IVM in relation to cannibalism. Soylent Green, the food derived from human remains, featured in the 1973 dystopian science fiction film also titled Soylent Green, was mentioned on a number of occasions (quote 3). While some of these comments were likely intended to be humorous, the conceptual link between IVM and Soylent Green is still of note. Other commenters addressed cannibalism with seemingly sincere concerns about its links to the development of IVM (quote 4). For some the concern was that IVM would lead to the culturing of human cells, while for others IVM represented a progression towards a world where cannibalism would be acceptable. Some commenters also raised concerns that IVM would lead to a scenario where people, particularly the poor, would be forced to eat IVM. A smaller number of commenters also suggested that IVM development was motivated by greed or political considerations (quote 5).

In vitro meat's impact on the environment Commenters often discussed the environmental implications of IVM, plant-based meat analogues and/or conventional meat production. While most commenters felt IVM would have a positive impact on the environment, some felt that it would be less efficient than conventional meat (quotes 6 and 7). Another group of commenters discussed the unsustainability of current levels and forms of meat production, but did not explicitly support IVM. Indeed, some commenters acknowledged the environmental challenges posed by conventional meat, but instead recommended solutions other than IVM. Lastly, a handful of commenters expressed doubt about the links between meat production and climate change.

\section{In vitro meat not needed}

Some commenters suggested that IVM is not needed because there is a better solution to addressing any issues associated with conventional meat production/consumption. Most commonly, commenters indicated that people should simply reduce or eliminate meat from their diets (quotes 8 and 9). Another common sub-theme was that people should consume local and/or organic meat rather than IVM (quote 10). A small number of commenters advocated for a switch a more natural diet in general terms.

\section{In vitro meat's impact on public bealth}

Another common theme focused on the impacts of IVM on human health and well-being. Issues discussed in this theme were related to fighting global hunger, nutrition and fat content, and food safety. Commenters who felt that IVM was a food-safety threat and less healthful than conventional meat were slightly more common than those who felt that IVM would yield direct health benefits (quotes 11 and 12). When fat content was addressed, commenters were mixed between discussing negative implications for taste and lauding benefits to health. There was, however, stronger support for IVM as a means of promoting global food security (quote 13). Lastly, several commenters noted the health benefits of eating meat, while others discussed the dangers of a meat-heavy diet.

\section{In vitro meat as a new scientific development}

The most commonly addressed theme related to IVM as a new technology. The most frequently identified sub-theme was that IVM was unnatural and therefore problematic (quote 14). Many of these commenters also used words such as 'lab' and 'test-tube' as negative descriptors, and some were also unable to distinguish between IVM and technologies such as cloning and genetic modification. Associated with this were multiple concerns about IVM leading to unintended and/or unknown consequences (quote 15). Several of these commenters also expressed distrust of the food system or technological innovation more generally. Others, however, argued that IVM was no more unnatural than current agricultural practices or technological developments. A large segment of commenters within this theme also expressed excitement about the scientific innovation underlying IVM and many 
also defended IVM as real meat and/or believed IVM would improve significantly with time (quote 16).

In vitro meat as a culinary development

Many commenters also framed IVM in the context of being a novel food for consumption rather than merely a scientific development. Most commonly, commenters expressed disgust or a 'yuck factor' at the consumption of IVM meat (quotes 17 and 18). Several commenters also explicitly noted they held negative perceptions of the taste and texture of IVM. By contrast, other commenters suggested that IVM would appeal to meat eaters or that it has the potential to taste better than conventional meat (quote 19). Several commenters also took the opportunity to describe their appreciation for the taste of meat and/or their rejection of plant-based meat analogues.

Structural-economic considerations and in vitro meat The structural-economic theme encompasses comments that discuss broader implications of and constraints on IVM production. Commenters generally posed questions about the IVM production process and many raised particular concerns about the use of fetal bovine serum (quote 20). The use of serum was also commonly mentioned with regard to the previously addressed 'yuck factor.' Several commenters were also concerned about the high initial price of IVM (quote 21). Few commenters expressed concern about the implications of IVM for farmers.

\section{Discussion}

The present study examined public perceptions of IVM through the qualitative analysis of user-generated comments on US-based online news articles discussing the first IVM hamburger. We discuss the findings in the context of challenges and opportunities facing efforts to propel IVM into a socially accepted sustainable alternative to conventional meat. While the discussion is specific to IVM, many of the challenges and opportunities appear relevant to novel technologies for sustainable diets more generally. We also highlight the potential role of the public health nutrition community.

\section{Challenges for in vitro meat}

As was anticipated by prior literature addressing IVM, much of the opposition to IVM arose out of the idea that it is unnatural and thus undesirable ${ }^{(2,20,29)}$. The rejection of the unnatural is also well established with regard to other technological innovations such as geoengineering and GM organisms ${ }^{(23,24,43)}$. As per Frewer et al. ${ }^{(25)}$ (p. 452), 'manipulating food and animals using "unnatural" biological techniques seem to strike a major negative, fundamental chord with many people...'. Unnaturalness was also closely tied to the sub-theme of disgust at the notion of eating IVM. Based on our findings, the yuck factor' is as much related to the perceived unnaturalness of the product as to specific concerns about taste and texture. Thus, this issue will not be resolved through technological development alone. Further, there was a trend across themes of expressing concern about IVM having unknown and/or harmful risks for human beings, the environment and the human-animal relationship. Thus, fear of the unknown and the novel, exacerbated by perceptions of unnaturalness, will be a clear hurdle for IVM to overcome. While additional information about IVM's health and environmental profile will help to allay some of the concerns, it is also clear that a strong regulatory structure will be needed to build trust in both the IVM production process and IVM itself. Members of the public health nutrition community may be able to play an important role both in working with the scientists who are developing IVM in order to ensure an optimal nutritional composition, as well as assisting with the knowledge translation process to ensure that members of the public are able to better make sense of any positive or negative health and environmental implications of novel food technologies such as IVM.

Those seeking to gain support for the further development of IVM based on current information about its profile may also wish to clearly distinguish IVM from GM organisms and cloning given the already existing antipathy for these technologies, particularly in light of the tendency for perceptions of new food technologies to be driven by generalised attitude towards food technologies that are perceived to share common characteristics, (25) (p. 454). Anchoring a new technology to previous contentious technologies in this manner may limit understanding and close off debate ${ }^{(10)}$.

Based on our findings, another key challenge for IVM promoters to overcome is the idea that IVM is inferior to conventional meat or vegetarian diets. This notion also factors into the theme of IVM as a dystopian vision, in which environmental and population challenges have forced us into a scenario where we will have to resort to eating an inferior and perhaps morally dubious product (for many commenters, paralleling the fictional scenario of Soylent Green). This suggests that efforts to gain public support for IVM should approach messages focusing on the justification for the development of IVM with some caution since they may feed into ideas of forced IVM consumption or having to resort to desperate measures to find food sources. Rather than suggesting that IVM is necessary in light of challenges such as climate change and population growth, it may be preferable to cast IVM as a product that stands on its own merits regardless of external circumstances. Traits relevant to public health nutrition such as nutritional content, taste and food safety then become particularly important.

A final challenge for IVM acceptance is found in the online IVM discourse itself. A quarter of all comments 
were found to be uncivil in nature. Anderson et al. ${ }^{(12)}$ found that uncivil online comments contribute to the polarization of risk perceptions around a given technology. These uncivil comments may lead already sceptical individuals to strengthen their view that IVM is a risky technology. Therefore, those supporting IVM as a sustainable alternative to conventional meat may wish to be mindful of online discourse surrounding IVM.

\section{Opportunities for in vitro meat}

Despite these challenges, several themes also reveal opportunities for the acceptance of IVM. Sub-themes favouring IVM were commonly found within the context of environment, public health, animal welfare and IVM as a new scientific development. In particular, the idea that IVM will be more sustainable than conventional meat, reduce animal suffering and/or help to alleviate global food insecurity appeared to resonate with commenters. Prior work has also shown that news sources regularly mention these benefits when covering $\mathrm{IVM}^{(20)}$. Our findings indicate that commenters address these same points when discussing IVM online. However, in light of the aforementioned concerns about IVM as a dystopian vision, it appears that some commenters interpret this information in a much more negative light. Some form of segmented marketing approach may eventually be needed to address this issue.

Perhaps more surprising was the common sub-theme of excitement about IVM because it represented an innovative scientific development. These individuals may become early adopters and thus important to building acceptance of $\mathrm{IVM}^{(44)}$. This group also signals some receptivity to the marketing of IVM as a new and attractive form of meat rather than a targeted solution to external constraints. Indeed, IVM is likely to have the biggest environmental and public health nutrition impact if it succeeds at appealing to individuals who enjoy eating large amounts of red meat, rather than niche groups who have already adopted largely plant-based diets. Once fully developed, IVM may represent a novel tool for nutritionists whose patients are reluctant to cut down on red meat. Finally, several commenters posed what appeared to be sincere questions about the production process. This signals a level of curiosity that enables critical thinking and represents an opportunity for IVM supporters to provide additional clarifying information about the production process $^{(10)}$.

\section{Limitations}

While comment analysis represents a valuable and unobtrusive approach to discerning themes in public perceptions, we wish to highlight three key limitations. First, we note that commenters are unlikely to be nationally representative and that reliable demographic information is not available for consideration. Additionally, online commenters may feel particularly strongly about a topic in order to have been compelled to comment. It is possible that non-commenters hold different opinions about IVM. Thus, while comments were more frequently opposed to IVM than supportive of IVM, we are not able to make any generalizations about the overall levels of support for IVM in the USA. Second, the framing of the issue in each individual article may have influenced perceptions of IVM. To partially account for this, we examined comments from a range of news sources to help avoid any bias associated with article framing or the readership or website design of any one particular source $^{(45)}$. Finally, it is not always possible to discern the true intent of a commenter or accurately discern sarcasm online. Thus, while some element of subjectivity is inevitable in qualitative research, we coded a small number of relevant comments as 'unclear' rather than speculate about their true intent.

\section{Conclusion}

Our findings suggest that while the environmental and food security motivations for IVM resonate with some segments of the population, others find that reasoning both uncompelling and problematic. Additionally, concerns about IVM as an unnatural and risky product appear to be a significant barrier to public acceptance of IVM. Supporters of IVM may wish to begin to develop and publicize an appropriate regulatory strategy for IVM to build public trust, as well as developing messaging strategies that cast IVM as a new food technology with benefits to individuals rather than primarily a needed solution to global challenges. Due to IVM's anticipated environmental and health co-benefits, those in the public health nutrition field can make an important contribution towards informed and civil debate in the emerging public discussion about IVM.

\section{Acknowledgements}

Financial support: This research received no specific grant from any funding agency in the public, commercial or notfor-profit sectors. Conflict of interest: None. Authorship: L.I.L. conceptualized and developed the study question and design. L.I.L. and M.A.C. conducted all data collection, coding, double-coding and analysis. L.I.L. and M.A.C. jointly authored the manuscript. Ethics of buman subject participation: No private information was collected or analysed in this study.

\section{References}

1. Datar I \& Betti M (2010) Possibilities for an in vitro meat production system. Innov Food Sci Emerg 11, 13-22.

2. Tuomisto HL \& Teixeira de Mattos MJ (2011) Environmental impacts of cultured meat production. Environ Sci Technol 45, 6117-6123.

3. Gerber PJ, Steinfeld H, Henderson B et al. (2013) Tackling Climate Change through Livestock - A Global Assessment of Emissions and Mitigation Opportunities. Rome: FAO; available at http://www.fao.org/docrep/018/i3437e/i3437e.pdf 
4. Yngve A, Margetts B, Tseng M et al. (2010) Climate change: time to redefine our profession. Public Health Nutr 13, 301-302.

5. Post MJ (2012) Cultured meat from stem cells: challenges and prospects. Meat Sci 92, 297-301.

6. Chan DSM, Lau R, Aune D et al. (2011) Red and processed meat and colorectal cancer incidence: meta-analysis of prospective studies. PLOS ONE 6, e20456.

7. Farvid MS, Cho E, Chen WY et al. (2014) Dietary protein sources in early adulthood and breast cancer incidence: prospective cohort study. BMJ 348, g3437-g3437.

8. Kaluza J, Åkesson A \& Wolk A (2014) Processed and unprocessed red meat consumption and risk of heart failure: prospective study of men. Circ Heart Fail 7, 552-557.

9. Haagsman HP, Hellingwerf KJ \& Roelen BAJ (2009) Production of Animal Proteins by Cell Systems. Utrecht: University of Utrecht, Faculty of Veterinary Medicine; available at http://new-harvest.org/wp-content/uploads/ 2013/03/production_of_animal_proteins_1207.pdf

10. Marcu A, Gaspar R, Rutsaert P et al. (2014) Analogies, metaphors, and wondering about the future: Lay sense-making around synthetic meat. Public Underst Sci (Epublication ahead of print version).

11. Poria Y \& Oppewal H (2003) A new medium for data collection: online news discussions. Int J Contemp Hospit Manage 15, 232-236.

12. Anderson AA, Brossard D, Scheufele DA et al. (2014) The 'nasty effect': online incivility and risk perceptions of emerging technologies. J Comput-Mediat Commun 19, 373-387.

13. Stephens N (2010) In vitro meat: zombies on the menu? SCRIPTed 7, 94-401.

14. Catts O \& Zurr I (2009) The Tissue Culture and Art Project The Remains of Disembodied Cuisine. http://tcaproject.org/ projects/victimless/cuisine-remains (accessed October 2013).

15. Forgacs G (2011) Are you ready for tissues you can 'print on demand'? http://www.tedmed.com/talks/show?id=7221\& videoId=6836\&ref=about-this-talk (accessed December 2013).

16. Maastricht University (2014) Cultured Beef Website. http:// culturedbeef.net/ (accessed December 2013).

17. Calkins CR \& Hodgen JM (2007) A fresh look at meat flavor. Meat Sci 77, 63-80.

18. van der Weele C \& Driessen C (2013) Emerging profiles for cultured meat; ethics through and as design. Animals $\mathbf{3}$, 647-662.

19. Chiles RM (2013) If they come, we will build it: in vitro meat and the discursive struggle over future agrofood expectations. Agric Hum Values 30, 511-523.

20. Goodwin JN \& Shoulders CW (2013) The future of meat: a qualitative analysis of cultured meat media coverage. Meat Sci 95, 445-450.

21. Miller J (2012) In vitro meat: power, authenticity and vegetarianism. J Crit Anim Stud 10, 41-63.

22. Hopkins PD \& Dacey A (2008) Vegetarian meat: could technology save animals and satisfy meat eaters? J Agric Environ Ethics 21, 579-596.

23. Corner A, Parkhill K, Pidgeon N et al. (2013) Messing with nature? Exploring public perceptions of geoengineering in the UK. Glob Environ Chang 23, 938-947.

24. Pidgeon N, Corner A, Parkhill K et al. (2012) Exploring early public responses to geoengineering. Philos Trans $R$ Soc $A$ 370, 4176-4196.

25. Frewer L, Bergmann J, Brennan K et al. (2011) Consumer response to novel agri-food technologies: implications for predicting consumer acceptance of emerging food technologies. Trends Food Sci Technol 22, 442-456.
26. Schurman R (2004) Fighting 'Frankenfoods': industry opportunity structures and the efficacy of the anti-biotech movement in Western Europe. Soc Probl 51, 243-268.

27. exMoor Pharma Concepts (2008) The In Vitro Meat Consortium Preliminary Economics Study Project 29071 V5. http://invitromeat.org/images/Papers/invitro\% 20 meat $\% 20$ economics\%20study\%20v5\%20\%20march\%2008. pdf (accessed December 2013).

28. Mattick CS \& Allenby BR (2012) Cultured meat: the systematic implications of an emerging technology. In Proceedings of the 2012 IEEE International Symposium on Sustainable Systems and Technology (ISSST), Boston, MA, USA, 16-18 May 2012, pp. 1-6; available at http://ieeexplore. ieee.org $/ \mathrm{xpl} /$ login.jsp?tp=\&arnumber=6228020\&url=http\%3A \%2F\%2Fieeexplore.ieee.org\%2Fxpls\%2Fabs_all.jsp\%3Farnum ber\%3D6228020

29. Welin S (2013) Introducing the new meat. Problems and prospects. Nord J Appl Ethics 7, 24-37.

30. Brossoie N, Roberto KA \& Barrow KM (2012) Making sense of intimate partner violence in late life: comments from online news readers. Gerontologist 52, 792-801.

31. Glenn NM, Champion CC \& Spence JC (2012) Qualitative content analysis of online news media coverage of weight loss surgery and related reader comments. Clin Obes $\mathbf{2}$, $125-131$.

32. Henrich N \& Holmes B (2011) What the public was saying about the H1N1 vaccine: perceptions and issues discussed in on-line comments during the $2009 \mathrm{H} 1 \mathrm{~N} 1$ pandemic. PLoS One 6, e18479.

33. Karlsson MB (2010) Participatory journalism and crisis communications: a Swedish case study of swine flu coverage. Observatorio (OBS*) 4, 201-210.

34. Rowe G, Hawkes G \& Houghton J (2008) Initial UK public reaction to avian influenza: analysis of opinions posted on the BBC website. Health Risk Soc 10, 361-384.

35. Regan Á, Shan L, McConnon Á et al. (2014) Strategies for dismissing dietary risks: insights from user-generated comments online. Health Risk Soc 16, 308-322.

36. Paskin D (2010) Say what? An analysis of reader comments in bestselling American newspapers. J Int Commun 16, 67-83.

37. Loke J (2013) Readers' debate a local murder trial: 'race' in the online public sphere. Commun Cult Critique 6, 179-200.

38. Brossard D (2013) New media landscapes and the science information consumer. Proc Natl Acad Sci U S A 110, 14906-14101.

39. Alliance for Audited Media (2014) Top 25 U.S. Newspapers for March 2013. http://www.auditedmedia.com/news/ research-and-data/top-25-us-newspapers-for-march-2013.aspx (accessed December 2013).

40. Elo S \& Kyngäs H (2008) The qualitative content analysis process. J Adv Nurs 62, 107-115.

41. Charmaz K (2006) Constructing Grounded Theory. A Practical Guide Through Qualitative Analysis. London: Sage Publications.

42. Papacharissi Z (2004) Democracy online: civility, politeness, and the democratic potential of online political discussion groups. New Media Soc 6, 259-283.

43. Deckers J (2005) Are scientists right and non-scientists wrong? Reflections on discussions of GM. J Agric Environ Ethics 18, 451-478.

44. Thogersen J, Haugaard P \& Olesen A (2010) Consumer responses to ecolabels. Eur J Mark 44, 1787-1810.

45. Milioni DL, Vadratsikas K \& Papa V (2012) 'Their two cents worth': exploring user agency in readers' comments in online news media. Observatorio (OBS*) 6, 21-47. 